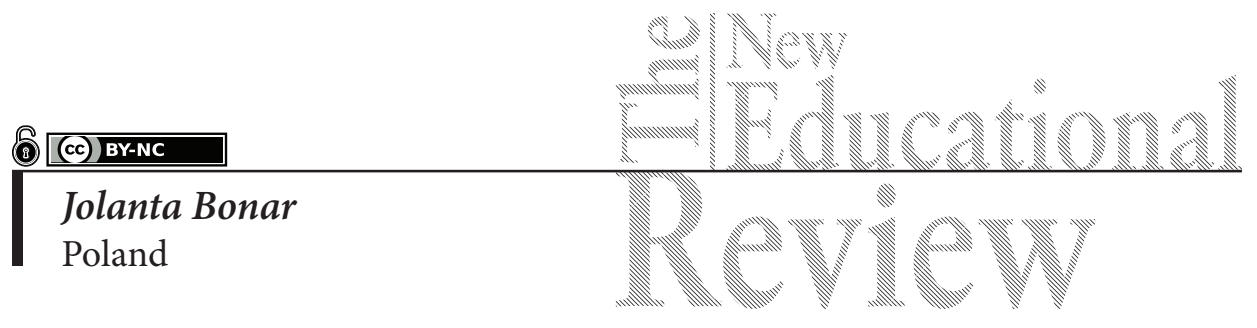

\title{
Using Creative Activities to Discover Children's Understanding of the World
}

DOI: 10.15804/tner.2019.58.4.01

\begin{abstract}
Cognition of the world, construction of knowledge related to our surroundings, and expressing meanings that stem from our life experiences are by no means easy processes. A substantial part of our knowledge remains dormant, but its extraction makes it possible to grasp children's visions of the world. Even if rarely applied in educational practice, creative activities remain a very effective approach to release children's conceptualisation of the world. This paper presents research results that demonstrate the efficiency of creative-thinking techniques in extracting children's visions of the world, as illustrated by the concept of the family. The study, which was conducted as a didactic intervention, was performed in the 2018-2019 school year on a group of younger pupils from a large city. The results reconstructed children's process of understanding the above-mentioned concept and revealed the possibilities behind creative psychodidactics.
\end{abstract}

Key words: understanding a concept, didactic intervention, creative activity.

\section{Introduction}

Children are constantly attempting to understand the world and continuously constructing their knowledge of themselves and their surroundings. From its earliest origins, the human-world relationship has been characterised by our ever-changing perception. We struggle with the reality around us, parsing it intel- 
lectually, thereby shaping our individual image of it. We build a structure that is a model of the world and consists of a certain system of inner projections which helps us to anticipate events and prepare to face them (Donaldson, 1978). Children create their own images of the world not only by listening to stories, but also by experiencing it, and yet a substantial part of their knowledge remains dormant. Its extraction renders it possible to grasp children's visions of the world and this is the main rationale behind this study, as it allows us to discover children's interpretative thinking, revealing their personal knowledge and methods of comprehending reality. The psychodidactics of creativity was the inspiration behind the search for favourable conditions which facilitate the development of a child's potential. It was also an attempt to identify barriers in the educational sphere.

\section{Theoretical Background for Selecting the Subject. Terminological Findings}

In defining creativity, the most legitimate reference seems to be the classical definition proposed by Władysław Tatarkiewicz, who described the phenomenon of modern creativity as pan-creationism.

There is a great deal of creativity when we define it this way: not only in what we do with the world and how we think about it, but also how we perceive it. (...) Whether we want it or not, we have to complement stimuli sent by the world and shape our own image of the world, since the sensations we receive are not complete and formulated; they must be consolidated, as they are only raw material

(Tatarkiewicz 1975: 291).

The degree of children's creativity is determined by four psychological ingredients: knowledge, cognitive skills, motivation and personal traits. When these are completely developed, we can speak of fully realized creativity. The cognitional ingredients of such creativity are processes responsible for the generation of new ideas, and above all, the process of divergent thinking along with support for the creative ways in which attention, perception, imagination and conceptual knowledge function. Emotional ingredients, on the other hand, include cognitive curiosity and 'phil-creative' emotions. The list of motivational ingredients includes a need for novelty and certain manifestations of self-motivation, e.g., having fun and playing, whereas personal factors involve traits related to openness, which enable the smooth and flexible generation of ideas (Cropley, 2001). 
Children's creativity is facilitated by an education that has grown from constructivism, based on the assumption that people construct knowledge creatively and build their own world not as a representation or reconstruction of the true world, but as a realistic and functional structure that they share with others (Siebert 1999: 5). What arises from this assumption is the specific characteristic of the didactic process and the related expectations of the pupil:

1. The starting point of learning is always the pupil's activity. The child's personal, intellectual efforts precede any information provided by the teacher or the textbook. Therefore, the structure of representation is built in accordance with natural processes of gaining knowledge, and personal procedural strategies precede communicative forms. Learning is a process of building new knowledge on the basis of a person's previously acquired knowledge and experience. Knowledge provided by the teacher is restructured in a manner that means it partially loses the original features given by the teacher, as it begins to reflect individual traits of the recipient's cognitive apparatus.

2. Learning includes the social negotiation of meanings. What makes group work a particularly desired form of learning is the fact that any increase in knowledge lies in the dynamic processing of meanings, their construction and reconstruction in the face of changing contexts, and their juxtaposition with various conceptions. Group work allows for negotiations with partners, triggers an exploratory way of speaking, and offers an opportunity to activate divergent thinking, to generate pupils' own ideas, solutions, policy strategies and interpretations of events, and to discover miscellaneous methods of perception, comprehension and explanation.

3. The effect of learning is the pupil's actively constructed, modifiable and developable personal knowledge, which springs from the child's cognitive curiosity, and requires self-reliance, as well as for them to extend the boundaries of the data provided, with new ideas and concepts which are generated. This knowledge enables the child to be dubious and questioning towards constructs, expressed by means of creative language that is full of analogies, comparisons, and metaphors. Pupils construct their own understanding by applying various strategies and techniques of creative thinking, i.e., posing questions, and drafting cognitive maps. The former are a verbalisation of what a given pupil knows about a given subject and also what else they would still like to learn about it. 'Asking questions may sometimes be "unfocused", i.e. a question may not always be consciously posed. Sometimes all that we are aware of is a nagging puzzle, or a niggling feeling that some- 
thing is not quite straight in our mind' (Craft 2000: 6). Another effective technique is cognitive maps, aimed at condensing textual information in graphic form. If it is assumed that information is processed in the form of concepts organised into maps and models, and that cognitive development has much in common with the development of concepts accomplished in the course of cognitive conflict, then the generation of cognitive maps should be perceived not only as a way to illustrate the conceptual structure, but also as a tool for its processing, questioning, and expanding (Novak \& Musonda, 1991; Sungur et al., 2001).

\section{The Research Problem}

The research focuses on the manner in which eight-to-ten-year-old children comprehend the concept of the family. It was presumed that this is the age at which young people's explanation of how social systems work becomes logically coherent, and that they can expound on the existence of certain relationships even if they cannot observe them directly (Schaffer 1996). The assigned research objective - i.e., recognition of children's ways of constructing meanings customarily given to the term of the family - was the basis for formulating the following research agendas: How do children understand the meaning of the term the family? What features attributed to the term the family do they consider to be important?

\section{Research Methodology}

This attempt to reconstruct meanings applied by children uses an approach from qualitative studies (Seale, Gobo, \& Gubrium, 2004; Silverman, 2005; Denzin \& Lincoln, 2005). The type, nature and organisation of qualitative research is vital in an educational situation, where it is seen in its full complexity and with changeability of its impacts - namely, as an area of diversely determined events (Silverman, 2005, Denzin \& Lincoln, 2005). The research approach implemented stems from the action-based paradigm (Reason \& Bradbury, 2008). The multidirectional and (by definition) open model of analyses made it possible to create circumstances that activated children's intellectual abilities within the framework of didactic intervention, which is essentially, 'an intentional creation of educational conditions - which cannot be found in the public education system - in order to observe learning processes in situations that conventional education institutions neither 
provide nor take into account' (Klus-Stańska, 2010: 132; cf. Touraine, 1973). In this case, it was the release of creativity obtained by application of creative-thinking techniques, which were presumed to facilitate and support the pupils' efforts when interpreting a difficult and complex term. Techniques of creative thinking are based on a non-directive style of working, and recognition of the right to self-reliance when formulating sincere and authentic statements. The effectiveness of such techniques increases if participants are comforted by psychological safety (unconditional acceptance exercised by those in charge; an atmosphere free of external evaluation; empathic understanding) and psychological liberty, which is not limited by the expectations of others and enables unrestrained thinking, feeling and acting. The application of such techniques is the effect of reflection upon the educational conditions which must be fulfilled in order to harmonise the educational discourse with the pupil's discourse, which is rooted in the world of individual experiences.

\section{Data Collection Methods}

In the course of this research, the following basic methods of qualitative data collection were applied: participant observation (Tunnicliffe \& Reiss 1999), and questioning of secondary sources - the product of children's creativity. The structure of the research required the implementor to take the role of an interpretatively engaged observer-participant (Angrosino 2007). Observations focused on both the actions and their effects on the pupils, and the recorded insights were juxtaposed with graphic representation of the pupils' creativity and digital recordings of their extensive statements and utterances - revealing processes of reconceptualization of the term the family.

\section{Participants}

The research focused on specifically selected groups of pupils and research areas. The participants were children aged 8-9 (46 second graders, including 24 girls and 22 boys) and aged 9-10 (44 third graders, including 23 girls and 21 boys). The studies were conducted in the school year 2018/2019 in selected primary schools of a large city (Łódź). The research was not restricted to a small and carefully selected group of pupils. Instead, it focused on a typical group with a variety of opinions, attitudes, and experiences. 


\section{Research Results}

Firstly, the analysed pupils were asked to generate an associogram (a map of associations). The association-based approach allows us, in a way much easier than through an interview, to reveal elements which constitute the semantic univerisum of the given term. This method is particularly valuable when those being surveyed do not wish to, or have no ability to express their opinions directly, or when they are not sufficiently cognisant of their views (Ferrara \& Friant 2015). Thus, participants were asked to separately write down all family-related associations that came to mind, and the written material was later used to construct a collective map of associations for the researched group.

The study of the material created indicates that children conceptualise the family in line with the first entry of the dictionary definition for the term (from the Dictionary of the Polish Language), which describes it as a married couple and their offspring, siblings, and those who are related by kinship and affinity. The surveyed pupils claimed that the family consists of the following people: mum, dad, grandparents, great grandparents, siblings, aunts and uncles, cousins, and of such representatives of other groups as neighbours, friends and playground buddies, as well as: godparents, friends, classmates, and Santa Claus. Children declared that parents were the most important people, which confirms that the family is a group whose central positions are occupied by the roles of mother and father. In other words, parents are of special importance to children, who perceive them as guardians, love them dearly and see them as role models. Even though the role played by the male and female parent (seen as authority figures) differs and is still linked to the traditional roles they play, both parents are equally important to their children.

The researched pupils recognise that the family is an emotional community in which, for its whole existence, there has been a mutual convergence of views and opinions, to the highest possible extent. For many, the home will become an emotional mainstay, and a place of mental wellbeing. The family members are united by relationships (taking care of one another, looking after and helping each other, assistance, friendship, we are together) and feelings (love, amity, joy, laughter, pleasure, trust, sadness, anger, strength, happiness, hearth and home). Notably, the highest position is occupied by love, which confirms that the family is a nuclear group, specifically organised and bonded by affection and acceptance of one another.

Children's associations go beyond the dictionary definition however, expanding the concept of the family to animals (dog, cat, hamster, goldfish, dwarf rabbit, guinea pig), places (house, room, backyard, garage, garden, summer house, sea, workplace, 
school), objects (bed, pillow, bicycle, car, stars, flowers, tree, photos, shell, the family heirloom, computer, TV set, phone, book, games, toys, teddy bear, clock, calendar), activities (eating, cooking, baking a cake, sleeping, waking up, resting, hugging, tickling, playing, reading, making a snowman, doing homework, trips and outings, shopping, tidying up, taking the rubbish out), and festive events (Christmas, Easter, birthday).

Further exploration of the children's experiences continued once appropriate conditions for interrogative thinking were created. The surveyed group was asked to think about what they would like to ask their family and to note down actual questions addressed to relatives. The technique applied stems from a conviction that questions posed by children deepen the understanding of their personal ways of thinking and facilitate their emergence. Below are the questions formulated by the surveyed children:

Who is the youngest/oldest in the family? Who is the smartest? Who is the bravest? Who is your dad? Who likes eating the most? Who is kind? Who likes you? Who loves you?

What do you like? What do you like doing together? What do you do on Sundays?

Where do you live? Where did you use to live before? Where do you work? Where is your family home? Where do you go on holiday? Where do you have fun together? Where is your brother? Where do you have your aunt/uncle?

When were you born? When did you come here? When will you be going on holiday?

How do your siblings play? How do you get on? How do you find time for everything? How do you get to school or work? How were you created? How do you eat? How do you spend your summer vacations?

Why are you together? Why do you have a large family? Why do you live together? Why do you like each other? Why do you help one another? Why did you choose England for your home? Why is the family so peaceful? Why did you buy a tree? Why did you buy a dog?

Who do you hang out with? Who are you friends with? Who do you go on holiday with? Who are you in a relationship with?

How did your parents meet? What is your surname? How do you spend your free time? What will the next member of your family be called? What do you look like?

Are you from here? Do you like/respect each other? Are you nice to your kids? Do the kids disturb you when you have important things to do? Are you happy? Are you kind to one another? Do you listen to music? Do you like going for a walk/to the park/ to the swimming pool? Do you live together? Do you live in a block of flats? Do you have a big house? Do you have a garden? Do you have a car/a campervan? Do you have 
a grandma/a grandpa? Do you have a turtle or a tortoise? Are you rich? Do you like fruit and veggies?

What habits do you have? What pets do you have? What family members do you have?

Questions formulated by children show that the family is not only diverse: Who is the youngest in the family?, Who is the oldest in the family?, Who is the smartest?, Who likes eating the most?, but also a collective that is dynamic and undergoes changes. It is a group which forms a relatively stable entirety, while being subject to dynamic transformations related mainly to the course of its individual members' lives. It also has its own past: When were you born?, When did you come here?, How did your parents meet?, Where did you use to live before?, present: What is your surname?, Where is your family home?, What do you look like?, Are you rich?, and future: When will you be going on holiday?

The family is a collective, working on its own shared goals and objectives, and characterised by a specific organisation and a clearly-defined system of roles assigned to its individual members: How do you find time for everything?, How do you get to school or work?, Do the kids disturb you when you have important things to do? It is a community which finds its own place in the world, aware of its own individuality, including all constituents of its tradition, i.e., values important for a given group of people and passed from generation to generation. Based on existing traditions, it develops its own ways: What habits do you have?, What do you like doing?, What do you do on Sundays?, Where do you go on holiday?, How do you spend your free time?, How do you eat? It also allows for participation in the world of arts and culture, which enables its members to develop their own talents and abilities: Do you listen to music?

Family members are united by multidimensional, legally, religiously and customarily sanctioned and changeable relationships, since it is an inner world exposed to external influences that reach it through various channels and shape its social and individual system of values and standards of behaviour: What do you like?, How do you get on?, Are you kind to one another?, Why do you help one another?, Are you happy? Not only do the children recognise the complexity of family relationships, but also their ambiguousness. Informal relationships, single-parenthood or childless marriages become more and more common and are perceived as manifestations of family life, which explains the following questions: Do you live together?, Who are in a relationship with?

Analysis of the questions allows us to conclude that the surveyed pupils perceive the family as a community that is diverse, changes dynamically, is united 
by numerous connections, and has its own traditions and habits. They are aware of the fact that the family can expand and generations change, which means that the pupils conceptualise the family in line with the second entry of the dictionary definition, thus perceiving it also as lineage.

Drawing analogies was another activity which activated the children's imagination and creativity and opened up an opportunity to discover the meanings they give to the family. Analogy is the relationship between two objects, based on the similarity of their external structures. Through analogy, a person may use their knowledge and experience in new circumstances on condition that the new problem is somewhat similar to what they have experienced before. Analogy consists of the compared component, known as the object, and the comparing component, called the medium, and it utilises the commonality of the two, facilitating a shift from one object to another, and allowing comprehension of difficult content, and finding desired and original comparisons.

Analogies drawn by the pupils supplemented the content of images of the family within their awareness. And they did so by presenting the family as a diverse collectivity: The family is like the cosmos, because the cosmos has a lot of planets and the family a lot of members., The family is like a tree - some are old, others are young, just like members of the same family are older and younger, which is characterised by specific dynamics: The family is like a tree, because it grows and expands, just like the family expands, and has its own history: The family is like a tree, because it has roots, The family is like a tree, because it has a lot of leaves, and the family has a lot of memories.

Analogies allowed for the family to be perceived as an emotional community: The family is like the cosmos, because its planets are together, just like people in the family, as a group characterised by a specific organisation and a specified system of roles assigned to its individual members: The family is like a bee hive, because sometimes there is a lot of turmoil there., The family is like a bus, because somebody controls it - on the bus, it's the driver and in the family, mum or dad, as a collective aware of its own individuality: The family is like a sock, because everybody has his own, as a group whose members cannot always be together: The family is like the cosmos, because some planets are far away from one another, just like some families are far away from each other, or who - at times - do not even know one another: The family is like a bus, because you can meet a lot of people, but we don't always know everybody in the family, and yet they remain connected by positive relationships and can always count on one another: The family is like a bus, because - just like on the bus you can help somebody, e.g., give up your seat - in the family you can also help others. 
The family enables a child's most basic emotional needs - love, affiliation and safety - to be satisfied. Each person desires to have someone dear and trustworthy. The satisfaction of such needs results in a sense of personal happiness and impacts the development of personality. The family is like the cosmos, because the family is beautiful and so are the planets., The family is like a heart, because you can't live without it., The family is like water, because it's equally necessary., The family is like the sun, because when we have it, we shine.

The metaphors created by children confirmed the range and diversity of family-related associations, and showed the pupils' potential, not only in fluency and flexibility, but also in originality of thought.

\section{Conclusions}

The designed didactic scenario, which applied techniques of creative thinking, generated favourable conditions for pupils to interpret a complex social term. A comparative analysis of the dictionary definition and the children's descriptions of the family shows differences between those features that are important for adult language users and the properties significant for children. Dictionary definitions do not provide comprehensive content when describing the meaning of the researched term and provide a limited selection of its identifying features. The definitions provided by the children are more abundant and original than their lexicographical counterparts, since they offer a more comprehensive picture on the subject matter by recording individual ideas and images related to it. Such images are diverse and indicate the enquiring and interrogative nature of their knowledge, which is now even more justified, since modern society has not yet created a type of the family that would reflect it the most. Instead, we are now facing a broad repertoire for family types. Undoubtedly, it is crucial to satisfy children's emotional needs of intimacy and safety, and to take care of them, e.g., by introducing them to the world of culture.

Analysis of the material allows us to grasp what is personal/ordinary/natural, to formulate postulates, and to generate a map of 'directions' which indicate the best methods of incorporating children's points of view in their perception of the reality in which they grow up. When free of a reductionist attitude, observation and reflection create an invaluable possibility to grasp surprising and non-stereotypical reactions, which should be considered as valuable (but not necessarily representative) in the whole picture of the phenomena being researched. They also make it possible to recognise pupils' precognition, to which teachers should 
refer in the process of education, and which ought to be taken into consideration when planning classes.

The abundance and diversity of the collected material also confirms the potential of creative-thinking techniques as an approach to extract meanings given to reality by pupils. Even if the knowledge related to the realm of creativity psychodidactics is more accepted and methods of creative activity are beginning to be applied more frequently in educational practice, they are still not used often enough as a tool to encourage children to interpret the world, and to extract its personal and original representations.

\section{References}

Angrosino, M.V. (2007). Doing Ethnographic and Observational Research. London: Uwe Flick.

Craft A. (2000). Creativity Across the Primary Curriculum: Framing and Developing Practice, London: Routledge.

Cropey A. J. (2001). Creativity in Education and Learning. A Guide for Teachers and Educators, London: Kogan Page.

Denzin, N.K., Lincoln, Y.S. (eds.) (2005). The Sage Handbook of Qualitative Research. Los Angeles: Sage Publications.

Donaldson M. (1978). Children's Minds. Glasgow: Fontana/Collins.

Ferrara, M., \& Friant, N. (2016). The application of a multi-methodology approach to a corpus of social representations. Quality \& Quantity, 50(3), 1253-1271. DOI 10.1007/ s11135-015-0203-3 (accessed: 20.04. 2018).

Klus-Stańska D. (2010). Dydaktyka wobec chaosu pojęć i zdarzeń (Didactics versus the Chaos of Concepts and Events). Warszawa: Wydawnictwo Akademickie Żak.

Novak J.D. \& Musonda D. (1991). A Twelve-Year Longitudinal Study of Science Concept Learning. American Educational Research Journal, 28 (1), 117-153.

Reason P., Bradbury H. (eds.) (2008). The Sage Handbook of Action Research. Participative Inquiry and Practice. Los Angeles: Sage Publications.

Schaffer H. R. (1996). Social Development. Oxford: Blackwell.

Seale C., Gobo G., Gubrium J. (eds.) (2004). Qualitative Research Practice, London: Sage.

Siebert H. (1999). Pädagogischer Konstruktivismus. Eine Bilanz der Konstruktivismusdiskussion für die Bildungspraxis. Neuwied - Kriftel: Luchterhand.

Silverman D. (2005). Doing Qualitative Research. A Practical Handbook. London: Sage.

Sungur S., Tekkaya C. \& Ömer G. (2001). The Contribution of Conceptual Change Texts Accompanied by Concept Mapping to Students' Understanding of the Human Circulatory System. School Science and Mathematics 101(2), 91-101.

Tatarkiewicz W. (1975). Dzieje sześciu pojęć (The Story of Six Concepts). Warszawa: PWN. Touraine, A. (1973). Production de la Société. Paris: Editions du Seuil.

Tunnicliffe S.D. \& Reiss M.J. (1999). Building a Model of the Environment: How Do Children See Animals? Journal of Biological Education, 33 (3), 142-148. 